\title{
The influence of the nanostructure on the effect of $\mathrm{CO}_{2}$ on the properties of Pd-Ag thin-film for $\mathrm{H}_{2}$ separation
}

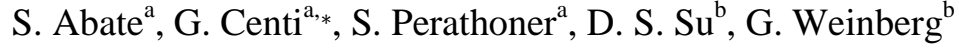 \\ ${ }^{a}$ University of Messina and INSTM/CASPE (Lab. of Catalysis for Sustainable Production and Energy), Dipartimen- \\ to di Chimica Industriale ed Ingegneria dei Materiali, V.le F. Stagno d'Alcontres 31, 98166 Messina, Italy \\ ${ }^{\mathrm{b}}$ Department of Inorganic Chemistry and ELCASS, Fritz Haber, Institute of the Max Planck Society, Faradayweg \\ 4-6, 14195 Berlin, Germany
}

*Corresponding author: e-mail centi@unime.it,

Received: 12 March 2010; Received in revised form 28 July 2010; Accepted 4 August 2010 Available online 12 August 2010

Dedicated to the friend Helmut Knözinger on in the occasion of his $75^{\text {th }}$ birthday for the seminal contribution to the advancement of fundamental knowledge on catalysis.

\begin{abstract}
The use of co-deposition instead of sequential deposition during the preparation of Pd-Ag thin films by electroless plating deposition leads to two different nanostructures, e.g. a dendritic nanostructure or a more compact and dense film, allowing to analyze the role of this parameter, at equal membrane composition, on the performances. In pure $\mathrm{H}_{2}$ the permeability to hydrogen of the second type of thin films is 3-4 times higher, but the presence of $\mathrm{CO}_{2}$ in the feed changes considerably the performances. The results are tentatively interpreted on the basis of a non-permanent in situ modification of the characteristics of the $\mathrm{Pd}-\mathrm{Ag}$ thin films, with creation of strains and microholes particularly enhanced for the nanostructure present in the sample prepared by co-deposition. These strains and microholes are suggested to derive from the combined effect of $\mathrm{CO}_{2}$ (with creation of subsurface $\mathrm{O}$ and/or $\mathrm{C}$ ) and of hydrogen diffusion through the thin film, which induces lattice expansion and stress on the nanograins. When the flux of $\mathrm{H}_{2}$ stops, there is a relatively rapid restoring of the initial situation. Scanning electron microscopy (SEM) characterization after the tests in the presence of $\mathrm{CO}_{2}$ indicates the presence of desintering consistently with above indications and the creation of crack like voids.
\end{abstract}

Keywords: Palladium; Thin films; Pd-Ag membrane; $\mathrm{H}_{2}$ separation; Nanostructure; $\mathrm{CO}_{2}$

\section{Introduction}

The use of metallic thin films for $\mathrm{H}_{2}$ separation is becoming of increasing relevance for sustainable chemistry and energy. In fact, the increasing demand of hydrogen has raised exponentially the need of new, more efficient processes for $\mathrm{H}_{2}$ production by hydrocarbon reforming. Steam reforming of natural gas is a wellestablished technology in refining and fertilizer industries for the production of hydrogen. Due to the thermodynamic limitations in this equilibrium endothermic reaction, the process requires high temperatures (around $900{ }^{\circ} \mathrm{C}$ ) to have enough methane conversion. However, the process is heat-transfer limited which decreases energy efficiency and causes an exergy loss. An efficient hybrid system (power + hydrogen) with a reduction in energy consumption of about $15 \%$ can be rea- lized by using a $\mathrm{H}_{2}$ membrane separation module downstream of a reforming reactor operating at about $650{ }^{\circ} \mathrm{C}[1-$ 4]. Advantages in the process efficiency and economics, as well as a reduction of greenhouse gas emissions per kilogram of $\mathrm{H}_{2}$ produced are thus possible.

A similar concept may also be applied to increase the energy efficiency and process economics of other industrially relevant reactions, such as the catalytic partial oxidation (CPO) of natural gas, the light alkane dehydrogenation to the corresponding alkenes or the water gas shift reaction [5]. Other relevant examples are the use of $\mathrm{H}_{2}$ permselective membranes in GTL technology to enhance the gasoline yields [6,7] and the integration of $\mathrm{H}_{2}$ membranes with PEM fuel cells to eliminate poisoning by $\mathrm{CO}$ and $\mathrm{CO}_{2}$ [8]. Pd-based thin films are usually utilized in such a type of $\mathrm{H}_{2}$ permselective membranes, because ideally (e.g. in defect-free membranes) the selectivity towards 
hydrogen is infinite [9-11]. In fact, $\mathrm{H}_{2}$ catalytically dissociates over Pd and may be transported through the membrane in the form of atomic hydrogen, while the transport of other atoms such as oxygen or carbon virtually does not occur. Therefore, it may be possible to selectively separate $\mathrm{H}_{2}$ from the complex mixtures such as those produced in the above cited reactions and typically containing carbon oxides, water and hydrocarbons.

Carbon oxides, and in particular $\mathrm{CO}$, have been reported in general to reduce the $\mathrm{H}_{2}$ permeation rate, although some authors have also indicated that carbon oxides may decompose over Pd membrane surfaces. Li et al. [12] observed $\mathrm{CO}_{2}$ dissociation above $250{ }^{\circ} \mathrm{C}$ yielding molecularly and/or dissociatively adsorbed $\mathrm{CO}$ below $400{ }^{\circ} \mathrm{C}$ and nanoscopic carbon deposits above $450{ }^{\circ} \mathrm{C}$. Mejdell et al. [13] instead indicated that $\mathrm{CO}$ and $\mathrm{CO}_{2}$ only inhibit surface reactivity of Pd-based membranes, and hence $\mathrm{H}_{2}$ permeability, by formation of strongly adsorbed species. Nguyen et al. [14] also concluded recently that the effect of $\mathrm{CO}$ is only that of competitive adsorption and is fully reversible.

On the other hand, Li et al. [15] reported the formation of a $\mathrm{Pd}_{1-\mathrm{x}} \mathrm{C}_{\mathrm{x}}$ phase in $\mathrm{Pd}$ membranes during separation of $\mathrm{H}_{2} / \mathrm{CO}$ mixtures, and the reversible incorporation of carbon into palladium. By treatment with $\mathrm{H}_{2}$ the carbon may be removed. Carbon derives from the dissociation of chemisorbed carbon monoxide. Studying the transient behavior in $\mathrm{H}_{2}$ permeance of Pd-based membranes after stopping the feed of $\mathrm{CO}_{2}$, Gielens et al. [16] found that carbon dioxide has a more complex effect than that of simple competitive chemisorption.

Therefore, the $\mathrm{H}_{2}$ permeance of Pd-based thin membranes is affected from the catalytic processes occurring on the surface, although there are discordances in literature about the effective nature of these effects, e.g. whether only competitive strong chemisorption, or instead phenomena related to the dissociation of carbon oxides. In general, the possibility of having diffusion of $\mathrm{C}$ and/or $\mathrm{O}$ in the $\mathrm{Pd}$ membrane is not considered, but in few cases the possibility of $\mathrm{C}$ diffusion has been reported.

In the catalysis area, it is well established that on Pd nanoparticles there is the possibility to have subsurface $\mathrm{C}$ and that this subsurface carbon may significantly influence the surface reactivity of Pd [17-19]. Low-coordinated Pd atoms, present at the nanoparticle edges, facilitate the formation and diffusion of carbon into tetrahedral subsurface sites. On these sites the reaction is almost non-activated [20]. Therefore, on smaller and more defective Pd nanoparticles the formation of subsurface $\mathrm{C}$ is enhanced. It is also known that subsurface $\mathrm{O}$ in $\mathrm{Pd}$ nanocrystals can influence the surface reactivity $[21,22]$.

The question is thus whether these observations on small Pd nanoparticles could be relevant also to interpret the effect of carbon oxides on the performances of Pdbased thin films, e.g. whether subsurface diffusion of $\mathrm{C}$ and/or $\mathrm{O}$ could occur after carbon oxides dissociation and the related influence on the surface reactivity of the membrane. We should comment regarding this aspect that Pdbased thin films could be prepared by different preparation methods, but a common method is by electroless plating deposition (EPD) [23-26]. The method used in this work is based on the decomposition of hydrazine over metallic $\mathrm{Pd}$ seeds. The electrons generated in this reaction give rise to in situ reduction of $\mathrm{Pd}^{2+}$ to $\mathrm{Pd}^{0}$ forming metallic Pd nanoparticles with a dendritic growing up to finally giving rise to a compact thin metallic film $[27,28]$. However, due to the mechanism of formation, the film should be better described as a dense assembly of nanograins.

Usually, to enhance the performances and especially the stability of Pd-based thin films, alloys with $\mathrm{Ag}, \mathrm{Cu}$ or other elements ( $\mathrm{Au}, \mathrm{Ru}$, etc.) are prepared [29,30]. $\mathrm{Pd}-\mathrm{Ag}$ membranes, with a typical silver amount of $23 \mathrm{wt} . \%$, are among the most common used. In these bimetallic thin films, two main variations in our preparation method by EPD could be cited: co-deposition and sequential deposition [25,31,32] of $\mathrm{Pd}$ and the second metal (Ag, in our case). These two methods lead to a different nanomorphology, the sequential method leading preferentially to a relatively dense and flat membrane, while the co-deposition gives preferentially a dendritic nanostructure. Therefore, thin films prepared by these two methods would have similar characteristics, but a different nanostructure. We suggest that they could act as a good model to understand the role of the surface nanostructure on the catalytic reactivity of the thin film, and the relevance of eventual subsurface $\mathrm{O}$ and $\mathrm{C}$ species on the surface reactivity and performances.

These effects are of more general value also for catalysis. In fact, the research interest on the use of these Pdbased thin films as catalysts is increasing. We reported in the past the use of these membranes for the catalytic selective reduction of nitrate in ground water [33]. Later, various authors have also investigated similar catalytic membranes for removing nitrates from groundwater [34,35]. We also used these membranes for the direct synthesis of $\mathrm{H}_{2} \mathrm{O}_{2}$ from $\mathrm{H}_{2}$ and $\mathrm{O}_{2}$ [36,37], and recently other research groups have investigated them in the same reaction $[38,39]$. Very interesting results have been also obtained using similar membranes for the catalytic direct oxidation of benzene to phenol [40-43]. In this system, the active oxygen species is formed on the surface of Pd via the reaction between oxygen and permeated hydrogen from opposite sides of the membrane. Hydroxylation occurs on the surface of Pd via reaction of the aromatic compound and active oxygen. Also in this case, the formation of subsurface $\mathrm{C}$ and/or oxygen species may possibly have a significant role on the surface reactivity. In fact, recent results have indicated that improved performances in the benzene direct hydroxylation could be obtained in Pd membranes prepared by EPD which leads to nanostructures characterized from an assembling of Pd nanograins. Benzene direct hydroxylation to phenol, in alternative to the three step commercial process, is industrially attractive as novel sustainable process, because it potentially allows a significant decrease in energy consumption and production of wastes, as well as an improvement in process safety [44].

Therefore, the surface reactivity of the Pd-based thin film could be affected by the presence of subsurface spe- 
cies and this effect is potentially relevant in their use both as membrane and catalysts. On the other hand, it is unclear whether the specific type of nanostructure of the Pd-based thin film has a role. However, classical methods for surface studies are not well suited to understand this question, because hydrogen absorbed in Pd thin films causes a lattice expansion [45] and this affects the subsurface diffusion of other species in palladium [46]. Therefore, in the absence of a flux of hydrogen through the thin film, not reliable data could be obtained.

Thus, we approached this question by comparing the behavior, particularly in terms of possible diffusion of $\mathrm{C}$ and/or $\mathrm{O}$ species through the palladium layer, of two thin film $\mathrm{Pd}-\mathrm{Ag}$ membranes prepared with the same composition, but using co-deposition or sequential deposition EPD methods. As will be shown here, the first thin film is characterized from a dense assembly of nanograins and dendritic nanostructure, while the second from a dense and amore compact film structure. Their comparison will allow to analyze the effect of the presence of amore defective nanostructure on the formation and diffusion of subsurface $\mathrm{C}$ and/or $\mathrm{O}$ species, and how this effect influences the surface reactivity and hydrogen permeability.

The scope of this manuscript is thus to evidence how a change in a preparation method for Pd-alloy thin film membranes, e.g. the use of a co-deposition instead of sequential deposition, leads to a significant change of the nanostructure of the $\mathrm{Pd}-\mathrm{Ag}$ thin film. This change has relatively minor impact on the $\mathrm{H}_{2}$ permeability with pure $\mathrm{H}_{2}$. On the contrary, the tests in the presence of $\mathrm{CO}_{2}$ evidence a significant change in the performances (time-on-stream dependence of the permselectivity in long term experiments, shows the influence of $\mathrm{CO}_{2}$ on hydrogen permeance). This effect is not permanent and is tentatively interpreted as the formation of reversible microholes, associated to strains and microholes deriving from the combined effect of $\mathrm{CO}_{2}$ (with creation of subsurface $\mathrm{O}$ and/or C) and of hydrogen diffusion through the thin film, which induces lattice expansion and stress on the nanograins.

Even with the limitations in passing from a thin film to discrete (dispersed) Pd-based nanoparticles, it may be suggested that this kind of phenomena are more general, and a relevant aspect to investigate is to determine the properties of supported Pd-based catalysts.

\section{Experimental}

\subsection{Preparation of the $P d-A g$ supported thin films}

Asymmetric porous $\alpha-\mathrm{Al}_{2} \mathrm{O}_{3}$ tubes (final layer porosity $70 \mathrm{~nm}$ ) provided by INOPOR, Germany, were used as the substrate for the deposition of Pd-based thin films [26,47-49]. The ceramic support is first cleaned from grease and other contaminations using purified isopropanol and then is dried at $100{ }^{\circ} \mathrm{C}$ for $3 \mathrm{~h}$. A thin film of $\mathrm{Pd}-\mathrm{Ag}$
Table 1: Composition of the plating bath used in the preparation of $\mathrm{M} 1$ and $\mathrm{M} 2 \mathrm{Pd}-\mathrm{Ag}$ thin films supported over ceramic alumina tubes.

\begin{tabular}{lccc}
\hline Chemical & M1 & \multicolumn{2}{c}{ M2 } \\
\cline { 3 - 4 } & $\mathrm{Pd}_{77} \mathrm{Ag}_{23}$ bath & Pd bath & Ag bath \\
\hline $\mathrm{PdCl}_{2}(\mathrm{~g} / \mathrm{l})$ & 5 & 5 & - \\
$\mathrm{AgNO}_{3}(\mathrm{~g} / \mathrm{l})$ & 1.24 & - & 1.24 \\
$\mathrm{EDTA}(\mathrm{g} / \mathrm{l})$ & 40 & 30 & 14 \\
$\mathrm{NH}_{4} \mathrm{OH}(25 \%)(\mathrm{ml} / \mathrm{l})$ & 290 & 290 & 290 \\
$\mathrm{~N}_{2} \mathrm{H}_{4}(1 \mathrm{M})(\mathrm{ml} / \mathrm{l})$ & 10 & 10 & 10 \\
Bath temperature $\left({ }^{\circ} \mathrm{C}\right)$ & 50 & 40 & 40 \\
pH & 11 & 11 & 11 \\
Time $(\mathrm{h})$ & 20 & 20 & 6 \\
\hline
\end{tabular}

(23 wt.\% Ag) was then deposited on these membranes by EPD method. The EPD technique consists of two main consecutive steps: (i) first Pd-based nanocrystals (seeds) are created on the membrane surface (seeding or activation step), and then (ii) deposition of $\mathrm{Pd}-\mathrm{Ag}$ layer occurs by reduction of $\mathrm{Pd}$ and $\mathrm{Ag}$ ions present in an aqueous solution in contact with the inner part of the alumina tube using the electrons generated in the decomposition of hydrazine over the Pd-based nanocrystals. The seeding procedure was described in detail before [26]. Two different procedures were used for this second step.

\subsubsection{Simultaneous deposition (co-plating)}

Pd and Ag were simultaneously deposited onto the porous support prior to be activated by direct impregnation of the palladium complex followed by reduction with hydrazine. The typical composition of the used plating bath is reported in Table 1 . The procedure could be repeated several times in order to increase the thickness of the deposited $\mathrm{Pd}-\mathrm{Ag}$ film. This membrane was called M1.

\subsubsection{Sequential deposition}

In the sequential procedure Pd an Ag layers were deposited consecutively. After surface activation palladium and silver depositions were performed using a bath composition shown in Table 1. After each deposition, the membrane was rinsed with deionised water, and then dried in an oven at $80{ }^{\circ} \mathrm{C}$ for $2 \mathrm{~h}$. This membrane was called M2.

The M1 and M2 membranes were finally treated in $\mathrm{N}_{2}$ flow for $5 \mathrm{~h}$ at $500{ }^{\circ} \mathrm{C}$.

\subsection{Characterization of the $P d-A g$ supported thin films}

The Pd-Ag supported thin films have been characterized by atomic force microscopy (AFM), scanning electron microscopy (SEM), electron-dispersive X-ray emission (EDX) mapping before and after reactivity tests. AFM characterization has been made using a Perception SPM from Assing (Italy), using contact mode operations. The tip used 

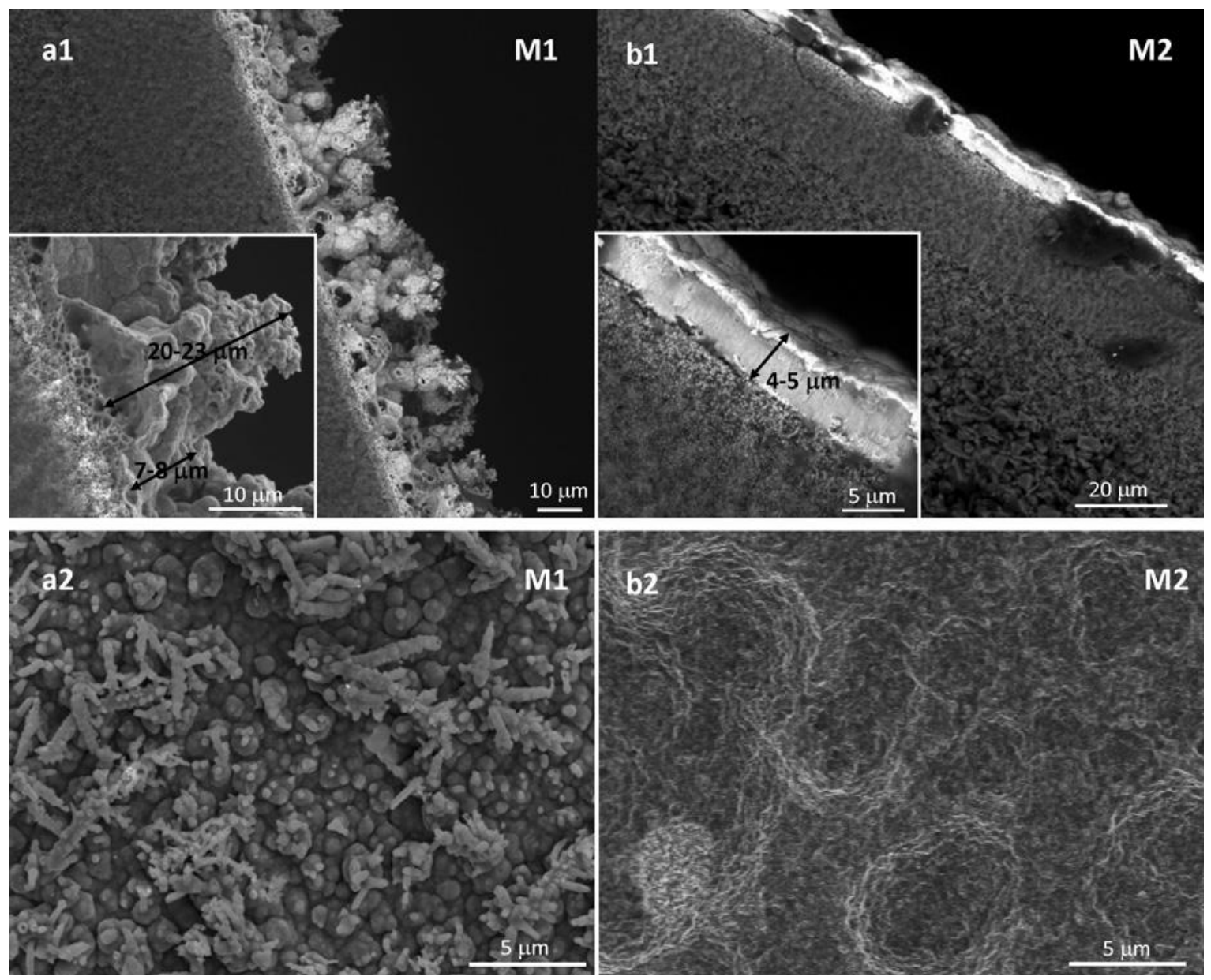

Fig. 1: SEM images of M1 (a1, a2) and M2 (b1, b2) thin films. Cross section (a1, b1) and top view (a2, b2).

was silicon nitride (Veeco), with a level $0.5 \mathrm{~N} / \mathrm{m}$ Au Reflex coating. EDX-SEM characterization studies of the membranes were made with a scanning electron microscope Jeol $5600 \mathrm{LV}(\mathrm{HV} 15 \mathrm{kV})$. Elemental analysis was carried out via energy dispersion analysis using an X-ray analytical system EDX OXFORD, coupled to the scanning electron microscope.

After membranes preparation the bubble point method was used to locate possible defects and pinholes, immersing the membrane in an ethanol/water mixture. Moreover, leak tests were made in order to analyze both the sealing of the graphite rings and the presence of cracks in the membrane, by pressuring the membrane with He up to a pressure of 9 bar, about 1.5 times higher than the maximum pressure used in permeability studies. No measurable flux (minimum detectable flow is $0.04 \mathrm{ml} / \mathrm{min}$ ), using a Bronkhorst digital massflowmeter (accuracy is $\pm 0.8 \%$ reading, $\pm 0.2 \%$ full scale) in the permeate side has been detected working at high temperature (about $450{ }^{\circ} \mathrm{C}$ ), before starting the separation tests. These tests were repeated at the end of experiments. Note that this method gives only indications about the presence of relatively large holes.

Permeability tests have been made in the stainless steel reactor (permeator) earlier described [26]. Both annu- lar ends between the membrane tube and the permeator wall were sealed with moulded graphite rings. The permeator was placed in an electrical furnace and heated to the desired temperatures (range $350-450{ }^{\circ} \mathrm{C}$ ).

A K-type thermocouple within the membrane tube was used to control the temperature during the permeation experiments. All gases were introduced into the permeator using a calibrated multichannel mass-flow controller. The inlet feed was connected to the inner side of the membrane and the permeated gases were measured on the outer side of the membrane, at atmospheric pressure. No sweep gas has been used. The pressure in the inner side of the tube was monitored via a pressure controller.

The permeation behavior of the membrane was measured with pure $\mathrm{H}_{2}$ at three different temperatures in the $350-450{ }^{\circ} \mathrm{C}$ range. Tests were made analyzing the $\mathrm{H}_{2}$ permeate flux as a function of time at fixed temperature and transmembrane pressure differential. A stable behavior is typically observed after few hours, but in some cases the time of the test was extended to have better indications on stability of operations. Then pressure differential across the membrane is increased ( $\Delta \mathrm{P}$ in the $0.5-5$ bar range) and the flux of $\mathrm{H}_{2}$ monitored again as a function of time-on-stream. 


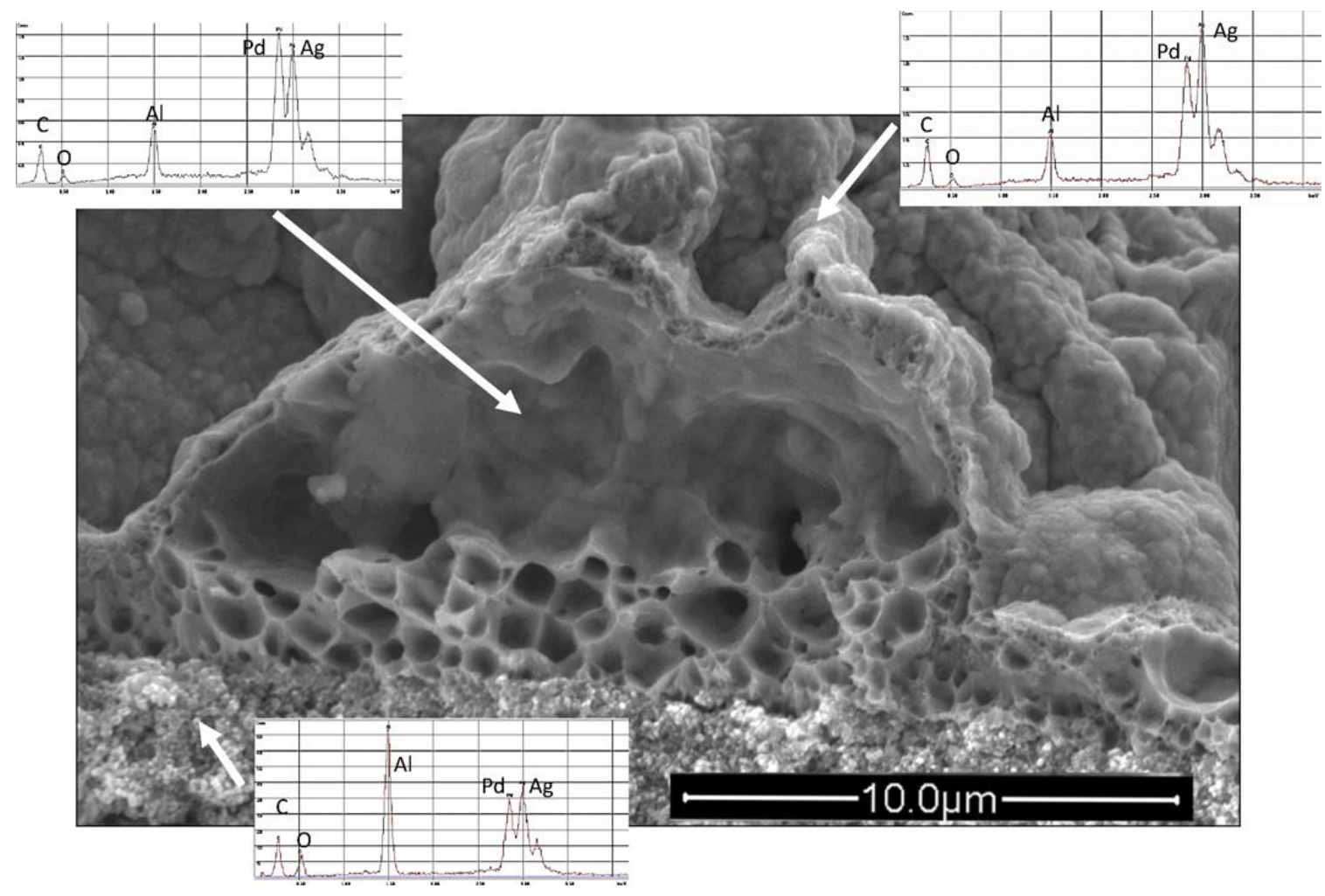

Fig. 2: SEM image of M1 thin film with EDX microanalysis of different areas.

The tests with a $\mathrm{H}_{2}: \mathrm{N}_{2}: \mathrm{CO}_{2}$ feed were made in the same experimental apparatus. In these tests, the amount of $\mathrm{CO}_{2}$ in the feed was changed between $10 \%$ and $20 \%$ at two different temperatures $\left(400-450{ }^{\circ} \mathrm{C}\right)$, while total pressure differential across the $\mathrm{Pd}-\mathrm{Ag}$ thin film was maintained constant at 2 bar. The flow rate of either permeate or feed gas were measured by a Bronkhorst digital mass flow meter, and feed mixture and permeate compositions were analyzed using a gas chromatograph (Agilent 3000A equipped with a Molsieve 5A column using Argon as carrier gas).

In these tests, the permeate flux was monitored as a function of time-on-stream for about 25-30 h, before the feed composition or the temperature were changed, and the permeate flux was monitored again as a function of timeon-stream for about 25-30 h. The membrane has been maintained in pure nitrogen flow for about $0.5-1 \mathrm{~h}$ between these consecutive tests, in order to stabilize the temperature or prepare the new feed composition. This time lag in pure nitrogen flow has been omitted in the figure summarizing the results (see later).

\section{Results and discussion}

\subsection{Characterization of the $P d-A g$ thin films}

SEM images evidence that the preparation by codeposition (M1) leads to a thin film characterized from a dendritic structure with faceted crystallites (Fig. 1, a1- cross section, a2 - top view). This effect is due likely to the different growth modes of Pd and Ag grains during electroless deposition. It has been observed that $\mathrm{Ag}$ is preferentially deposited on the Pd seed nuclei, and therefore Ag tends to shield active $\mathrm{Pd}$ particles and inhibits the plating reaction [50]. The resulting Pd-Ag layer is macroscopically homogeneous (by EDX mapping), but shows a significant roughness as shown in Fig. 1 and at nanoscale level the composition may result inhomogeneous.

The film results thus as a dense assembly of nanograins with size ranging from 100 to $300 \mathrm{~nm}$, having a core rich of Pd and an outer shell rich in Ag. The film thickness varies from 7-8 to 20-23_m(see inset in Fig. 1(a1)). Fig. 2 reports a largeSEMimage of the film which evidences that the inner part of the thin film has a sponge-like nanostructure, but apparently with limited or even absent connectivity between the voids and a denser top layer of thickness 200-300 nm.

EDX analysis evidences that the outer surface is richer in silver, while the inner part richer in Pd (Fig. 2).

The thin film prepared by sequential deposition (M2) (Fig. 1(b1) and (b2), cross section and top view, respectively) shows a homogeneous layer with a lower roughness than M1, and a higher compactness of the films. Although the cross section image (see inset in Fig. 1(b1)) suggests the presence of a relatively flat surface, the top view (Fig. 1(b2)) evidences the presence of grains, which are significantly larger than those in the case of M1 thin film. 

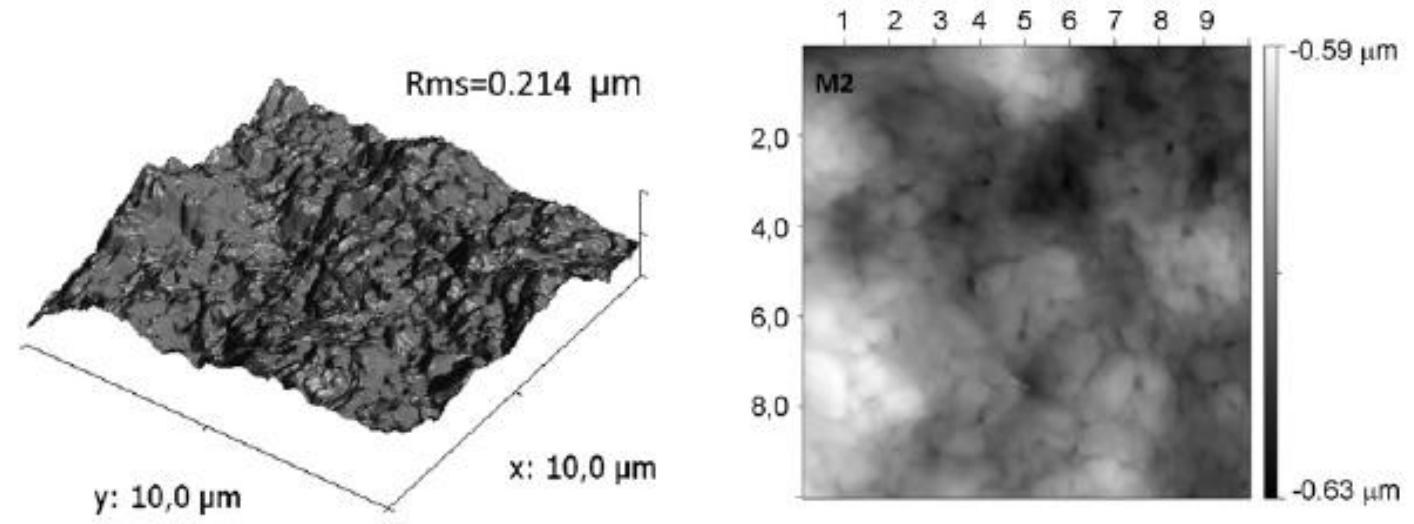

Fig. 3: AFM mapping of the surface roughness and nanomorphology of M2 thin film.
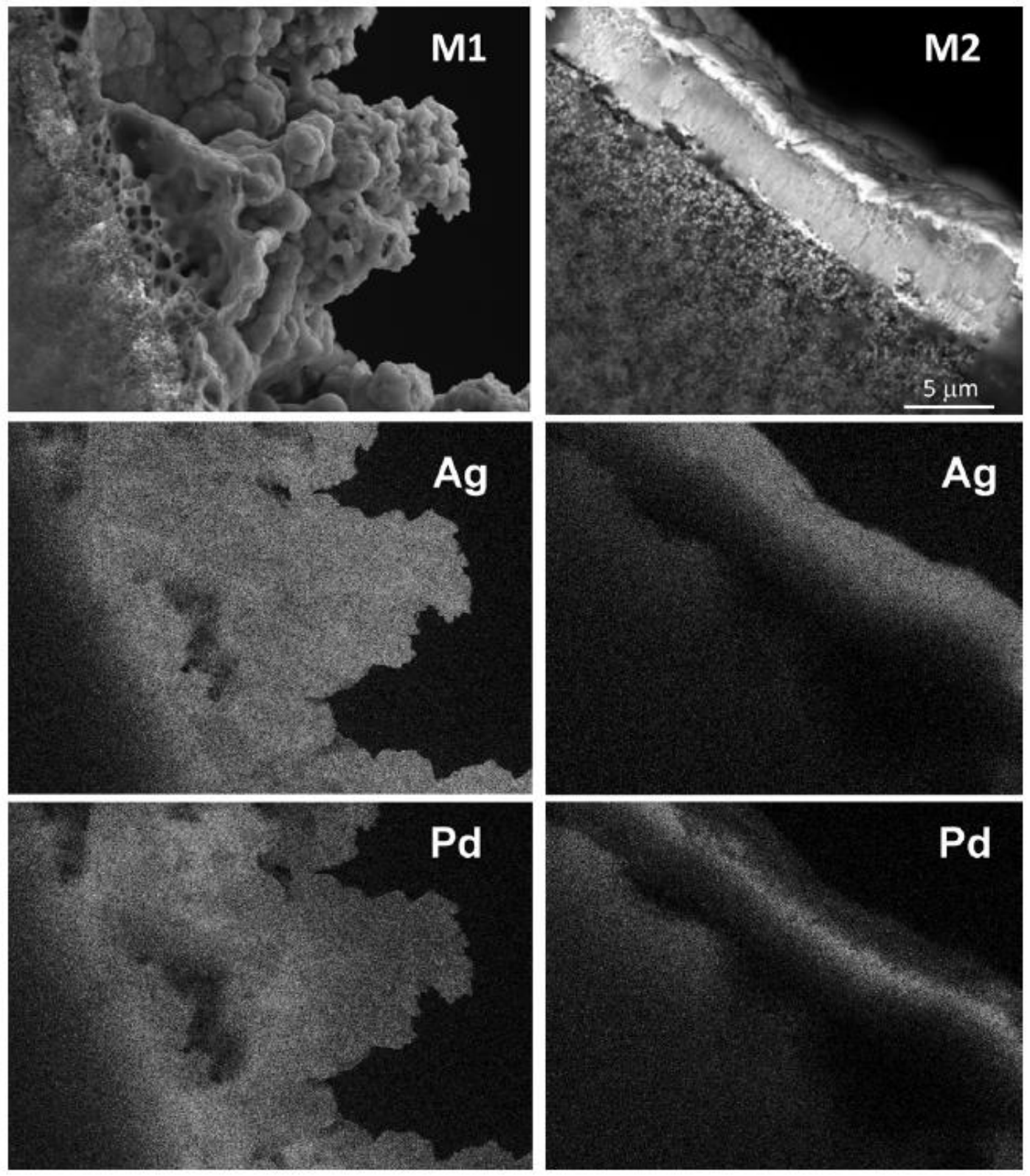

Fig. 4: SEM images of the cross section of M1 and M2 thin films, and relative mapping of Ag and Pd obtained by EDX analysis. 


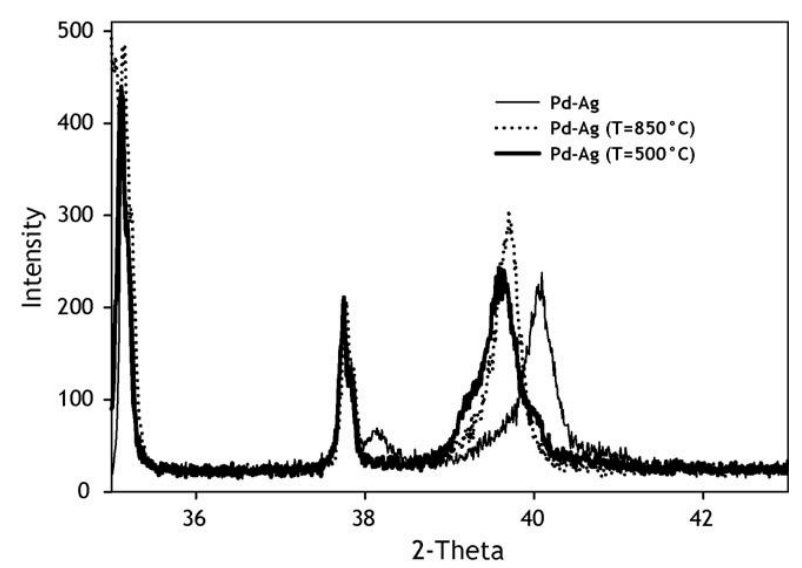

Fig. 5: Comparison of the XRD patterns of $\mathrm{Pd}-\mathrm{Ag}$ thin films after the plating stage and after the consecutive annealing in $\mathrm{N}_{2}$ flow at 850 or $500{ }^{\circ} \mathrm{C}$.

AFM images of the sample (Fig. 3) confirm the presence of grains with mean size of $0.5-1 \mu \mathrm{m}$ and a mean surface roughness (Rms) of about $0.2 \mu \mathrm{m}$. Due to the high surface roughness, it is not possible to analyze by AFM the M1 sample, but the SEM images (Fig. 1(a1) and (a2)) clearly evidences the presence of an order of magnitude higher roughness (Rms over $5 \mu \mathrm{m}$ ) and a one order of magnitude lower mean dimension of the grain size. Fig. 4 reports the mapping of Pd and $\mathrm{Ag}$ (by EDX-SEM) in the two M1 and M2 thin films. While the M1 sample shows an apparent homogeneous distribution of $\mathrm{Pd}$ and $\mathrm{Ag}$, although with the local differences remarked before (see Fig. 2), the concentration of $\mathrm{Ag}$ in the top layer of this film is evident for M2 sample. This is in agreement with the sequential deposition method. In both thin films there is preferentially Ag on the surface, but due to the presence of smaller nanograins in M1 an apparent better distribution is present.

From the characterization of M1 and M2 thin films we may conclude that the change from co-deposition to sequential deposition of $\mathrm{Pd}$ and $\mathrm{Ag}$ during the preparation of these materials by EPD method leads mainly to the formation of one order magnitude smaller nanograins and higher surface roughness due to the dendritic growing which is accentuated in M1 sample. The consequence is also a different degree of compactness of the two thin films. In both cases there is a surface enrichment in $\mathrm{Ag}$ at the level of grain size, although on a large scale the M1 sample appears more homogeneous in terms of Pd and $\mathrm{Ag}$ distribution.

We feel, however, that this is a consequence of the different nanostructure. We have not conclusive evidences, whether at the grain level the surface is richer in Ag in M2 case with respect to M1. On the other hand, surface techniques such as XPS have not the necessary spatial resolution to provide reliable indications. By EDX local mapping, there are limited differences at the interface region (grain boundaries), but this technique is only indicative. We could thus suggest that the main difference between the two samples is the nanostructure in terms of grain assembling, be

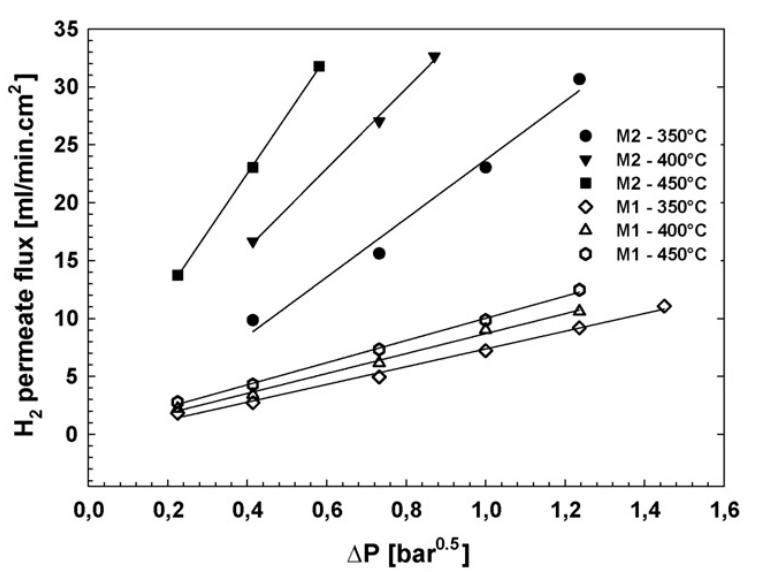

Fig. 6: Relationship between hydrogen permeation flux and the difference in the square root of hydrogen pressure between the tube-side and the shell-side $(\Delta \mathrm{P})$ at different temperature for $\mathrm{M} 1$ and M2 thin films.

ing M1 characterized from smaller grains and a more open dendritic arrangement. M2 has one order of magnitude larger grains and a dense and compact flat-type arrangement. Silver is preferentially located at the surface of grains.

Note finally, that the characteristic morphology of the M1 thin film is not a consequence of an insufficient annealing. The X-ray diffraction (XRD) patterns of the $\mathrm{Pd}-$ $\mathrm{Ag}$ thin film obtained after EPD ( $\mathrm{Pd}-\mathrm{Ag})$, and after annealing at $850{ }^{\circ} \mathrm{C}\left(\mathrm{Pd}-\mathrm{Ag} \mathrm{T}=850{ }^{\circ} \mathrm{C}\right)$ or $500{ }^{\circ} \mathrm{C}(\mathrm{Pd}-\mathrm{Ag} \mathrm{T}=$ $500{ }^{\circ} \mathrm{C}$ ) in $\mathrm{N}_{2}$ flow are reported in Fig. 5. The film immediately after plating $(\mathrm{Pd}-\mathrm{Ag})$ consists of individual $\mathrm{Pd}$ and $\mathrm{Ag}$ seeds without formation of the $\mathrm{Pd}-\mathrm{Ag}$ alloys. The annealing in nitrogen at $500{ }^{\circ} \mathrm{C}$ gives rise to the formation of the $\mathrm{Ag}-\mathrm{Pd}$ alloy as shown from the shift of the (llll) reflection of $\mathrm{Pd}$ from about $2 \Theta=40.1-39.78(\mathrm{Pd}-\mathrm{Ag})$ and the simultaneous disappearance of the $\mathrm{Ag}$ reflection at about 38.18. Further annealing at higher temperature $\left(850{ }^{\circ} \mathrm{C}\right)$ does not further change the situation, leading instead to the creation of large amounts of cracks and defects on the thin film.

\subsection{Permeability to $\mathrm{H}_{2}$ of the thin films}

The results, for permeation with pure $\mathrm{H}_{2}$, are reported in Fig. 6 at three different temperatures in the 350$450{ }^{\circ} \mathrm{C}$ range.

Tests were made analyzing the $\mathrm{H}_{2}$ permeate flux as a function of time at a fixed temperature and transmembrane pressure differential. After reaching a stable $\mathrm{H}_{2}$ permeate flux, the pressure differential across the membrane is increased ( $\Delta \mathrm{P}$ in the $0.5-5$ bar range) and the flux of $\mathrm{H}_{2}$ monitored again as a function of time-onstream. The results reported in Fig. 6 indicate that the permeation rate of $\mathrm{H}_{2}$ is directly proportional to $\Delta P=P_{f}^{0.5}-P_{p}^{0.5}$, e.g. the difference in the square roots of hydrogen pressures between the 
feed (f) and the permeation (p) sides of the thin membrane film. This is consistent with Sievert's law [51]:

$J_{\mathrm{H}_{2}}=\frac{Q}{\delta}\left(P_{f}^{n}-P_{p}^{n}\right)$

where $\mathrm{J}_{\mathrm{H} 2}$ is the transmembrane flux of $\mathrm{H}_{2}$, Q the permeability and $\delta$ the thickness of the $\mathrm{Pd}-\mathrm{Ag}$ membrane. The exponent $\mathrm{n}$ varies between 0.5 , when the rate-limiting step is the bulk transport of hydrogen across the thin metallic film, to 1.0 , when the surface dissociation of hydrogen is the limiting step [52].

Table 2 summarizes the dependence of the permeance from the temperature on the two thin films M1 and M2. The values of R2 obtained during the linear regression are also reported, which give an indication of the good fitting of the data.

Table 2: Permeance as a function of the temperature for M1 and M2 thin films and values of R2 in linear regression of the data reported in Fig. 5.

\begin{tabular}{llllll}
\hline \multirow{2}{*}{$T\left({ }^{\circ} \mathrm{C}\right)$} & \multicolumn{2}{l}{$Q / \Delta z\left[\mathrm{~cm} \mathrm{~min}^{-1} \mathrm{bar}^{-0.5}\right]$} & & \multicolumn{2}{l}{$R^{2}$ (from linear regression) } \\
\cline { 2 - 3 } \cline { 6 - 6 } & \multicolumn{1}{c}{$\mathrm{M} 1$} & $\mathrm{M} 2$ & & $\mathrm{M} 1$ & $\mathrm{M} 2$ \\
\hline 350 & 7.28 & 23.24 & & 0.9925 & 0.9783 \\
400 & 8.84 & 38.20 & & 0.9945 & 0.9889 \\
450 & 10.53 & 57.13 & & 0.9947 & 0.9887 \\
\hline
\end{tabular}

The $\mathrm{H}_{2}$ permeability of the two thin films is in agreement with the values reported in literature, taking into account the difficulty in comparing the results due to the wide range of reaction conditions used [52-54]. Obtaining the permeance by dividing the permeability by the membrane thickness is formally correct only for a compact (homogeneous) layer. In our case, quite different characteristics of the thin films are present. Even with this limit, it is useful to have a rough estimation of the permeability and activation energy in the two membranes.

The experimental values of $\mathrm{H}_{2}$ permeance $(\mathrm{Q} / \delta)$ at different temperatures were used to estimate the activation energy for $\mathrm{H}_{2}$ permeation, using an Arrhenius plot (Fig. 7). For both samples there is a good linear fit of the data, with a value of the regression coefficient (R2) of 0.998 and 0.994 for M1 and M2 samples, respectively.

The activation energy of the M1 thin film was found to be $17.5 \mathrm{~kJ} / \mathrm{mol}$, while that of M2 $42.8 \mathrm{~kJ} / \mathrm{mol}$. The lower value for M1 tentatively suggests that amixed mechanism of hydrogen transport through the membrane could be present.

To note that the M2 membrane has characteristics close to those often reported for dense thin-film Pd-based membrane, while the M1 membrane show a very high surface roughness and a dendritic nanostructure which makes from one side less precise the estimation of the permeance and activation energy, and from the other side has a probable influence on the mechanism of transport. We tentatively suggest that the difference between the M1 and M2 mem

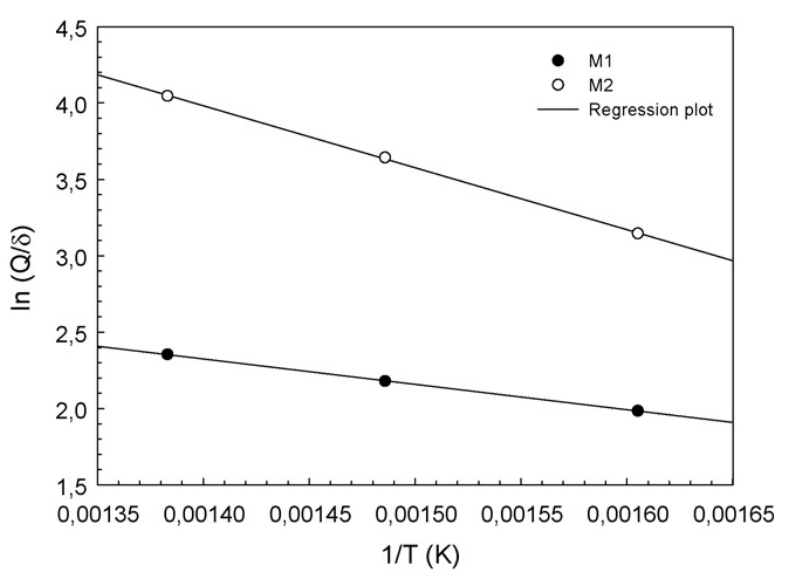

Fig. 7: Arrhenius plot of the relationship between the $\mathrm{H}_{2}$ permeance and temperature in M1 and M2 thin films.

branes could be related to the presence in M1 of a mixed diffusion mechanism (grain and intergrain, see later) and this is the cause of the low activation energy [26]. However, this is an aspect which deserves more studies.

In conclusion, permeability tests to $\mathrm{H}_{2}$ of the two thin films M1 and M2 indicate that M2, due to the more uniform and lower mean thickness shows a higher permeate flux of $\mathrm{H}_{2}$ at the same conditions. However, the permeance (the permeability divided by the mean film thickness) in the studied temperature range is not very different. If fact, the mean film thickness may be estimated to be around three times larger in M1 with respect to M2 thin film, but particularly for the M1 sample the great uncertainly on the value, due to the characteristic nanomorphology of the film (Fig. 1), do not allow more precise estimations.

The more than twice value of the activation energy for hydrogen diffusion in the film for M2 sample suggests a difference in the $\mathrm{H}$ transport through the film. Being the composition and experimental conditions the same, we believe that the possible explanation is related to the different nanostructure of the film. The interface region between the grains, where silver is predominant, is higher in the M1 sample, due to the presence of significantly smaller grains. Therefore, diffusion in the boundary region between grains [55] with respect to the classical bulk diffusion mechanism in Pd [23] could be enhanced. Similarly, the presence of nanovoids, although not connected each other's or with the surface, will affect the transport mechanism.

Barlag et al. [56] reported that the macroscopic hydrogen diffusion coefficient in homogeneous $\mathrm{Pd}_{1-\mathrm{x}} \mathrm{Ag}_{\mathrm{x}}$ alloys remains nearly constant up to silver concentrations of about $25 \%$. Then it falls off reaching a minimum value at $60 \%$ silver content before increasing again with rising silver content directly towards the value for pure silver, which is nearly the same as for Pd. At smaller silver contents the silver atoms partly block the energetically favored diffusion paths in the Pd matrix leading to round-about way diffusion. At high silver concentrations, Pd atoms act as traps for hydrogen in a silver matrix. The interplay of the hydrogen transport via two kinds of occupation sites with differ 


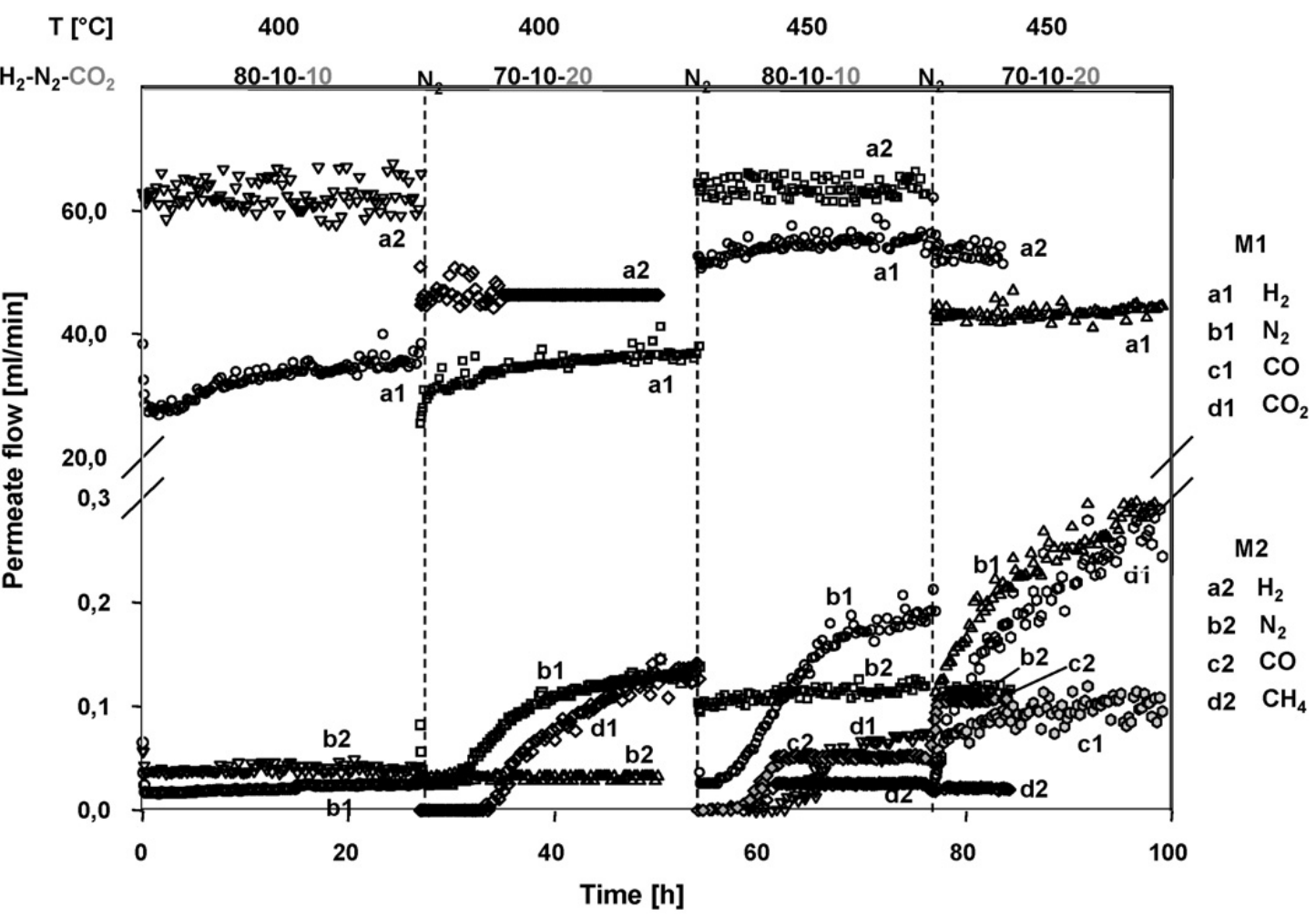

Fig. 8: Flux of $\mathrm{H}_{2}$ and other components in the permeate side as a function of time-on-stream during a sequence of experiments feeding mixtures of $\mathrm{H}_{2}: \mathrm{N}_{2}: \mathrm{CO}_{2}$ at 400 and $450{ }^{\circ} \mathrm{C}$ on $\mathrm{M} 1$ and $\mathrm{M} 2$ thin films.

ent hydrogen solubility determines the shape of the curve for the macroscopic diffusion coefficient as a function of the alloy composition. Therefore, in silver-rich intergrain regions, hydrogen could efficiently diffuse, but through a different mechanism with respect to that present in pure $\mathrm{Pd}$ or $\mathrm{Pd}-\mathrm{Ag}$ alloy, when the $\mathrm{Pd} / \mathrm{Ag}$ ratio is above four.

\subsection{Influence of $\mathrm{CO}_{2}$ on the transport of $\mathrm{H} 2$ through the thin films}

Fig. 8 reports the permeate flux of $\mathrm{H}_{2}$ and other species detected on the permeate side of the thin film as a function of time-onstream for both M1 and M2 samples. The behavior is monitored for about $25-30 \mathrm{~h}$ of time-onstream, before to change the feed composition and/or the temperature, as indicated in the figure. Note that the samples have been maintained for about $0.5-1 \mathrm{~h}$ in inert gas flow $\left(\mathrm{N}_{2}\right)$ during each of these changes, but for conciseness this time lag has been not included in Fig. 8. The feed in these tests is composed of principally $\mathrm{H}_{2}$ plus $\mathrm{N}_{2}$ and $\mathrm{CO}_{2}$ in variable amounts (in the $10-20 \%$ range). We use a high retentate flow rate coupled with the $\mathrm{Pd}-\mathrm{Ag}$ deposited in the inner part of the ceramic membrane to have a turbulent flow which together with a low degree of conversion of $\mathrm{H}_{2}$ and other gas components suggests the absence of polarization effects [57], although computer fluidodynamic simulations (CFD) would be necessary for more precise conclusions. To note also that the time to reach stationary retentate composition is less than $1 \mathrm{~h}$. Therefore, the transient effects observed (on a time scale of hours) are not determined from the transient related to establish uniform composition. This conclusion is supported from the fact than in M2 membrane the nearly stationary composition at $400{ }^{\circ} \mathrm{C}$ in the permeate membrane side establishes within less than about 15 min (see below).

The analyses of the retentate-side flow at the outlet of the membrane reactor indicate that still hydrogen is in very large amount and that neither $\mathrm{CO}$ nor $\mathrm{CH}_{4}$ could be detected, except traces. Note that retentate indicates the portion of the feed that does not pass through a cross flow membrane, while permeate is the part of the flow that passes through the membrane. The results in Fig. 8 refer to only the permeate flux of $\mathrm{H}_{2}$ and other species. Note also the change in scale in Fig. 8 y axis.

The observation that $\mathrm{CO}$ and $\mathrm{CH}_{4}$ are detected only at the permeate side and not at the retentate side (absence or presence in very low amounts), indicates that they cannot be associated to a simple transport by Knudsen or viscous flow transport through holes in the thin film. This conclusion is also supported from the observation of the time-onstream behavior. For example, in the tests at $450{ }^{\circ} \mathrm{C}$ $\left(\mathrm{H}_{2}: \mathrm{N}_{2}: \mathrm{CO}_{2}=80: 10: 10\right)$, the formation of $\mathrm{CO}$ and $\mathrm{N}_{2}$ slowly grows with time-on-stream in M1 thins film, differently from M2 thin film.

A possible interpretation of this effect is that with time-onstream nanoholes form and this effect causes a progressive increase in the amount of $\mathrm{N}_{2}$ and $\mathrm{CO}$ being trans 

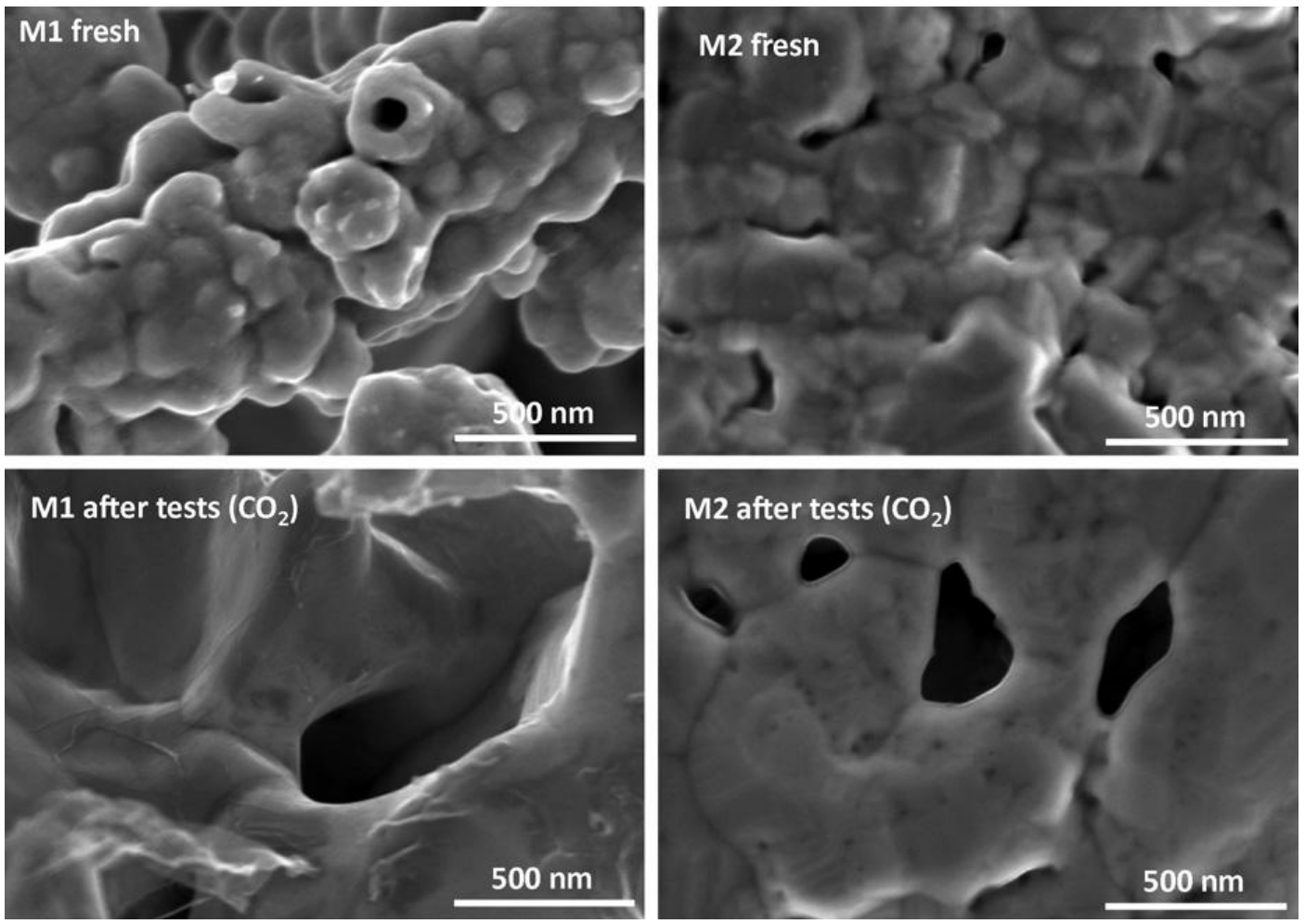

Fig. 9: SEM images of M1 and M2 thin films before (fresh) and after the tests with the presence of $\mathrm{CO} 2$ in the feed.

ported through the film by Knudsen diffusion or viscous flow. $\mathrm{CO}$ is not detected in the retentate side, but may derive from the decomposition of $\mathrm{CO}_{2}$ during the transport through the film. According to this interpretation, it should be a permanent modification of the thin film and thus the initial amount of the same species during the consecu tive experiments at higher temperature $\left(450{ }^{\circ} \mathrm{C}\right)$ should be equal or higher than the final amount observed at $400{ }^{\circ} \mathrm{C}$. On the contrary, we observed that the initial amount is very low, and then grows again with time-on-stream. Changing the feed composition at the same temperature, the initial amount is again initially low and then grows with time-onstream. Note that during these switches in the experimental conditions the membrane is kept in the reactor at the same temperature, but in inert $\left(\mathrm{N}_{2}\right)$ flow. Therefore, the results do not indicate an effect of permanent modification of the membranecharacteristics. On the other hand, the effect in M2 membrane is not present at $400{ }^{\circ} \mathrm{C}$ and at $450{ }^{\circ} \mathrm{C}$ for the $10 \% \mathrm{CO}_{2}$ concentration in the feed, but it is present at 450 ${ }^{\circ} \mathrm{C}$ for the $20 \% \mathrm{CO}_{2}$ in the feed. This result clearly evidences that the effect cannot be attributed to the time to establish an equilibrium through the membrane and within the membrane reactor.

One possible interpretation could be related to reversible strains in the thin film nanostructure which derives from the lattice expansion caused from hydrogen diffusion through the thin film. This is reasonably a slow process, and thus a time from 10 to $20 \mathrm{~h}$ could be necessary to fully develop. During the time lag between the two consecutive experiments, the reduction of hydrogen partial pressure (e.g. the use of $\mathrm{N}_{2}$ flow) would reduce the amount of hydrogen present in the thin film, and as a consequence these nanoholes close again. The alternative explanation is the presence of dissociation of $\mathrm{N}_{2}$ and $\mathrm{CO}_{2}$ at the retentate side, transport of the atoms through the thin film and then recombination at the permeate side. Possibly a combination of the two effects could be present.

The nanostructure of the thin film has a significant role on these effects. In fact, the slow growing of $\mathrm{N}_{2}$ and carbon oxides is generally observed in all the consecutive tests for M1 sample, apart from the initial ones at the lower temperature and $\mathrm{CO}_{2}$ concentration in the feed. On the contrary, the amount of these species in the permeate side is generally constant with time-onstream for all the tested temperatures and feed compositions in the case of M2 thin film. The presence of nanograins and a less dense nanostructure inM1thus favor the presence of the described phenomena.

The presence of $\mathrm{CO}_{2}$ significantly influences the behavior of the thin M1 and M2 films, but in a different way depending on the nanostructure. In fact, in pure $\mathrm{H}_{2}$ at 400 ${ }^{\circ} \mathrm{C}$, the flux of $\mathrm{H}_{2}$ passing through the M2 thin film is about three times that through M1 film (Fig. 6). However, in the presence of $10 \% \mathrm{CO}_{2}$, the difference is reduced to about 1.1-1.5, and to $1.1-1.2$ for $20 \% \mathrm{CO}_{2}$ (Fig. 8). At $450{ }^{\circ} \mathrm{C}$ the effect is even larger, reducing from over 4 to about 1.1. It may be also noted that at $400{ }^{\circ} \mathrm{C}$ the increase of $\mathrm{CO}_{2}$ concentration from $10 \%$ to $20 \%$ has no effect on the $\mathrm{H}_{2}$ permeate flow of $\mathrm{M} 1$, while it reduces the $\mathrm{H}_{2}$ permeate flow of M2 by $20 \%$. This observation is not consistent with the 
hypothesis of only a competitive chemisorption of $\mathrm{CO}_{2}$ on the sites for $\mathrm{H}_{2}$ dissociation.

It is possible also to note that at $400{ }^{\circ} \mathrm{C}$, the flow of $\mathrm{H}_{2}$ through the M1 thin film increases by about $15 \%$ during about $25 \mathrm{~h}$ of time-onstream, while it is constant in the case of $\mathrm{M} 2$ thin membrane. The effect is present both using $10 \%$ and $20 \% \mathrm{CO}_{2}$ in the feed, although in the latter case, the increasing concentration of $\mathrm{N}_{2}$ and $\mathrm{CO}_{2}$ in the permeate side (in small amounts) is detected differently from the case using $10 \% \mathrm{CO}_{2}$. This effect is instead not present using the M2 thin film, where the low and constant amounts of N2 are related to only some leakage of $\mathrm{N}_{2}$ from atmospheric air in the pipe to the analysis system.

At $450{ }^{\circ} \mathrm{C}$ the situation is more complex, because in both $\mathrm{M} 1$ and $\mathrm{M} 2$ thin films the increase of $\mathrm{CO}_{2}$ causes a lowering of the $\mathrm{H}_{2}$ permeate flux, although as mentioned above, the two samples have very close performances, despite the four times different behavior in pure $\mathrm{H}_{2}$. Other differences are the following:

- The $\mathrm{N}_{2}$ amount in the permeate side for M2 thin film is constant, while increases in the case of M1 sample.

- $\mathrm{CH} 4$, although in very low amounts, is observed for $\mathrm{M} 2$ sample, but no $\mathrm{CO}_{2}$, as for M1 sample.

- $\quad \mathrm{CO}$ is observed in both M1 and M2 cases (at the higher temperature and $\mathrm{CO}_{2}$ concentration), but the amount is essentially constant for M2 sample, while grows with time-on-stream for the M1 sample.

In conclusion, the two M1 and M2 thin films have a quite different sensitivity in the presence of $\mathrm{CO} 2$ in the feed and their time-on-stream behavior shows differences which cannot be explained only on the basis of a competitive chemisorption of $\mathrm{CO}_{2}$ on the surface and an inhibition of hydrogen dissociation. Note also that in both cases no evidence have been found, after separation tests, of the presence of carbon species on the surface of the thin film (see later), at least at temperatures equal or below $450{ }^{\circ} \mathrm{C}$. The detection of $\mathrm{CO}$ in the permeate is indicative of the presence of dissociation of carbon dioxide, but this effect is present only in the tests at $450{ }^{\circ} \mathrm{C}$ and not at $400{ }^{\circ} \mathrm{C}$ (Fig. 8).

At $400{ }^{\circ} \mathrm{C}$ the main difference between the two thin films is that M1 apparently has less sensitivity to $\mathrm{CO}_{2}$, and that the flux of hydrogen passing through the thin film increases with the timeon- stream, although the effect is reversible. In fact, after changing the feed composition from $10 \%$ to $20 \% \mathrm{CO}_{2}$ (during the change in the feed composition, the sample is maintained in flux of $\mathrm{N}_{2}$ for about $0.5-1$ h), the flux of $\mathrm{H}_{2}$ starts again from a lower value increasing later with the time-on-stream. Note that the process of hydrogen diffusion through a Pd thin film is fast enough to be not seen on the time scale of the experiments reported in Fig. 8. In agreement, in the case of M2 sample, no effect is observed and the $\mathrm{H}_{2}$ flux through the thin film maintains constant with time-on-stream. The effect observed for M1 sample should be thus associated to a reversible modification in the thin film characteristics, and reasonably to the different nanomorphology and nanostructure with respect to $\mathrm{M} 2$.

A possible explanation is the formation of strains and microholes associated to expansion of the lattice due to $\mathrm{H}_{2}$, which should be enhanced in M1 sample with respect to M2, and may be a reversible effect as commented before. However, this explanation is in contrast with the observation of the three times higher hydrogen permeability of M2 with respect to M1 using pure $\mathrm{H}_{2}$ (Fig. 6), and the much reduced difference in behavior when $\mathrm{CO}_{2}$ is present. In addition, the increase in the flux of hydrogen for M1 sample was not observed using pure $\mathrm{H}_{2}$ in the feed. Therefore, the formation of strains and microholes occurs when $\mathrm{CO}_{2}$ is present in the feed and probably is associated to a partial decomposition of $\mathrm{CO}_{2}$ and subsurface $\mathrm{O}$ and/or $\mathrm{C}$ diffusion. Although $\mathrm{CO}$ is detected in permeate only at the higher temperature and concentration of $\mathrm{CO}_{2}$, it is probable that the amount formed is too low to be detected in the continuous experiments of Fig. 8 at lower temperatures and $\mathrm{CO}_{2}$ concentrations. It is thus mainly the reaction of $\mathrm{CO}_{2}$ with specific sites, probably associated to defective positions in the boundary region of the grains. When the amount of subsurface $\mathrm{O}$ and/or $\mathrm{C}$ reaches saturation, the reaction progressively stops. Preliminary XPS studies confirm the presence of subsurface $\mathrm{C}$ in the thin films after reaction, but this analysis will be part of a consecutive paper on this topic.

The interpretation of the phenomenon is thus that $\mathrm{CO}_{2}$ has a similar competitive effect on hydrogen dissociation in the two thin films, but in M1 the partial dissociation of $\mathrm{CO}_{2}$ and reasonably $\mathrm{O}$ and/or $\mathrm{C}$ sublattice diffusion (enhanced in M1 with respect to M2 due to the nanostructure) combined with the lattice expansion due to $\mathrm{H}$ diffusion induces the presence of strains and microholes which favor the $\mathrm{H}_{2}$ transport (together with other gases) through the thin film. Dissociation of $\mathrm{CO}_{2}$ and the specific nanostructure are the two necessary conditions which determine the formation of reversible strains and microholes in M1 thin film.

Due to the presence of these reversible strains and microholes, an additional flux through the M1 thin film is present which partially compensates the inhibition by $\mathrm{CO}_{2}$ chemisorption. For this reason, the large differences in the hydrogen fluxes using pure $\mathrm{H}_{2}$ between $\mathrm{M} 2$ and $\mathrm{M} 1$ samples, is progressively reduced on increasing the $\mathrm{CO}_{2}$ concentration in the feed (Fig. 8).

\subsection{Characterization of the thin films after the tests in the presence of $\mathrm{CO}_{2}$}

Previous discussion has pointed out the concept of a reversible in situ modification of the characteristics of the Pd-Ag thin films, with creation of reversible strains and microholes particularly enhanced by the nanostructure present in M1 sample. These strains and microholes derive from the combined effect of $\mathrm{CO}_{2}$ and of hydrogen diffusion through the thin film. When the flux of $\mathrm{H}_{2}$ stops, there is a relatively rapid restoring of the initial situation. It 


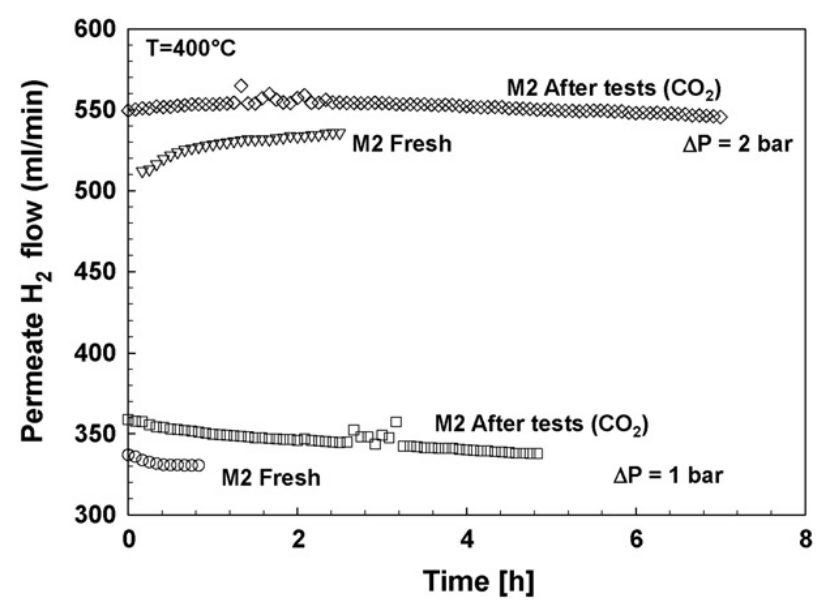

Fig. 10: Permeate flow of $\mathrm{H}_{2}$ as a function of time-on-stream for 1 or 2 bar of differential pressure across the thin film for $\mathrm{M} 2$ thin film before and after the tests with the presence of $\mathrm{CO}_{2}$ in the feed.

is thus evident that the characterization of the phenomenon requires operating in situ with the flow of hydrogen flowing through the membrane in the presence of $\mathrm{CO}_{2}$, but this is technically quite challenging. Nevertheless, it may be interesting to analyze by electron microscopy the thin films after the tests with $\mathrm{CO}_{2}$.

The results are summarized in Fig. 9 which report the SEM images (top view) of M1 and M2 thin films before and after the tests with $\mathrm{CO}_{2}$. A microstructural evolution of the thin film may be observed with a desintering effect, e.g. with an increase of the surface instead of the minimization of the surface free energy. Note also that no evidences could be observed for the presence of surface carbon or carbon-like species.

Sudre and Lange [58] have modeled the effect of inclusions on the desintering phenomenon of ceramic powders. Their model concerned the breakup of grain bridges linking polycrystalline clusters. This breakup phenomenon results in the formation of large crack like voids. The mechanism that produces this breakup phenomenon (desintering) is a function of the grain size to bridge length ratio. When the ratio exceeds a critical value, the bridge will break up, e.g. disinter, to reduce the free energy of the system. This instability condition depends on the presence of inclusions in the bridge length or from stress conditions on the grain size. Reasonably the same considerations are valid also in our case. Therefore, the formation of subsurface $\mathrm{O}$ and/or $\mathrm{C}$, and the stress induced from lattice expansion upon inclusion of hydrogen determine the desintering and the creation of crack like voids. In agreement with the presence of smaller grains, larger voids are observed by SEM in M1 sample after the tests with $\mathrm{CO}_{2}$ with respect to M2 sample (Fig. 9). Therefore, even with the limits in the analysis mentioned above, SEM characterization of the samples confirms the previous conclusions.

However, it may be argued that apparently these SEM images do not indicate the reversibility of the formation of strains and microholes in the thin film. It is thus necessary to compare the permeability of the thin film in tests in pure $\mathrm{H}_{2}$ before and after the tests with $\mathrm{CO}_{2}$. The results for M2 thin film are shown in Fig. 10 and similar results were also observed for M1 sample. The behavior at two differential pressures across the thin film ( 1 or 2 bar) was measured.

Fig. 10 evidences that the permeate $\mathrm{H}_{2}$ flow after the tests with $\mathrm{CO}_{2}$ is slightly higher than that of the fresh sample, but only about $4 \%$ higher. Some permanent pinholes thus form, but in low amount, and do not justify thus the much higher differences observed in the tests with $\mathrm{CO}_{2}$.

\section{Conclusions}

The use of co-deposition instead of sequential deposition during the preparation of $\mathrm{Pd}-\mathrm{Ag}$ thin films by electroless plating deposition leads to two different nanostructures. The first sample shows a dendritic nanostructure, with the formation of one order magnitude smaller nanograins and higher surface roughness with respect to the sample prepared by sequential deposition. The latter has the typical dense characteristics of metallic thin films for $\mathrm{H}_{2}$ separation, with a thickness of about $4-5 \mu \mathrm{m}$. The permeability to $\mathrm{H}_{2}$ of the thin films prepared by sequential deposition about 3-4 times higher than that of the sample prepared by co-deposition, which shows however a lower activation energy for hydrogen diffusion. Silver tends to accumulate at the boundary region between the grains. The presence of $\mathrm{CO}_{2}$ in the feed, however, changes considerably the performances and the behavior of the two thin films in hydrogen diffusion. The results indicate a reversible in situ modification of the characteristics of the $\mathrm{Pd}-\mathrm{Ag}$ thin films, with creation of reversible strains and microholes particularly enhanced for th nanostructure present in the sample prepared by co-deposition (M1). These strains and microholes derive from the combined effect of $\mathrm{CO}_{2}$ (with creation of subsurface $\mathrm{O}$ and/or $\mathrm{C}$ ) and of hydrogen diffusion through the thin film, which induces lattice expansion and stress on the nanograins. When the flux of $\mathrm{H}_{2}$ stops, there is a relatively rapid restoring of the initial situation. SEM characterization after the tests in the presence of $\mathrm{CO}_{2}$ indicates the presence of desintering consistently with the above indications and the creation of crack like voids.

In conclusion, the results presented here evidence the original aspect that both the particular nanostructure and the presence of $\mathrm{CO}_{2}$ in the feed (probably associated to the formation of subsurface $\mathrm{O}$ and/or carbon atoms) influence the properties and the nanomorphology of $\mathrm{Pd}-\mathrm{Ag}$ thin films, and together with the presence of desintering phenomena. We feel that this is a more general phenomenon present also in other Pd-based bimetallic films and of more general interest to understand the performances and characteristics of Pd-based thin films which interest as membranes and catalysts is growing. The role of strains in determining the catalytic performances of supported Pdalloy particles is under active discussion. Therefore, the results presented here open new aspects to understand the 
catalytic reactivity of supported Pd-alloy catalysts, although this should be specifically investigated for these catalytic materials.

\section{Acknowledgements}

\section{References}

[1] D. Barba, F. Giacobbe, A. De Cesaris, A. Farace, G. Iaquaniello, A. Pipino, Int. J. Hydrogen Energy 33 (14) (2008) 3700-3709.

[2] M. De Falco, D. Barba, S. Cosenza, G. Iaquaniello, A. Farace, F.G. Giacobbe, Asia-Pacific J. Chem. Eng. 4 (3) (2009) 259-269.

[3] G. Iaquaniello, F. Giacobbe, B. Morico, S. Cosenza, A. Farace, Int. J. Hydrogen Energy 33 (22) (2008) 6595-6601.

[4] M. De Falco, D. Barba, S. Cosenza, G. Iaquaniello, L. Marrelli, Int. J. Hydrogen Energy 33 (20) (2008) 5326-5334.

[5] A. Brunetti, G. Barbieri, E. Drioli, Chem. Eng. Sci. 64 (2009) 3448-3454.

[6] M.R. Rahimpour, H. Elekaei, Fuel Proc. Technol. 90 (2009) 747-761.

[7] A.A. Forghani, H. Elekaei, M.R. Rahimpour, Int. J. Hydrogen Energy 34 (2009) 3965-3976.

[8] A. Brunetti, G. Barbieri, E. Drioli, Chem. Eng. Proc. 47 (2008) 1081-1089.

[9] Ø. Hatlevik, S.K. Gade, M.K. Keeling, P.M. Thoen, A.P. Davidson, J.D. Way, Sep. Purif. Technol. 73 (2010) 59-64

[10] S. Adhikari, S. Fernando, Ind. Eng. Chem. Res. 45 (3) (2006) 875-881.

[11] N.W. Ockwig, T.M. Nenoff, Chem. Rev. 107 (10) (2007) 4078-4110.

[12] H. Li, A. Goldbach, W. Li, H. Xu, J. Phys. Chem. B 112 (2008) 12182-12184.

[13] A.L. Mejdell, M. Jøndahl, T.A. Peters, R. Bredesen, H.J. Venvik, Sep. Purif. Technol. 68 (2009) 178-184.

[14] T.H. Nguyen, S. Mori, M. Suzuki, Chem. Eng. J. 155 (2009) 55-61.

[15] H. Li, A. Goldbach, W. Li, H. Xu, J. Membr. Sci. 299 (1-2) (2007) 130-137.

[16] F.C. Gielens, R.J.J. Knibbeler, P.F.J. Duysinx, H.D. Tong, M.A.G. Vorstman, J.T.F. Keurentjes, J. Membr. Sci. 279 (12) (2006) 176-185.

[17] D. Teschner, E. Vass, M. Hävecker, S. Zafeiratos, P. Schnörch, H. Sauea, A. Knop-Gericke, R. Schlögl, M. Chamam, A. Wootsch, A.S. Canning, J.J. Gamman, S.D.Jackson, J. McGregor, L.F. Gladden, J. Catal. 242 (1) (2006) 26-37.

[18] H. Gabasch, K. Hayek, B. Klötzer, A. Knop-Gericke, R. Schlögl, J. Phys. Chem. B 110 (10) (2006) 4947-4952.

[19] F. Studt, F. Abild-Pedersen, T. Bligaard, R.Z. Sørensen, C.H. Christensen, J.K. Nørskov, Angew. Chem. Int. Ed. 47 (48) (2008) 9299-9302.

[20] F. Vines, C. Loschen, F. Illas, K.M. Neyman, J. Catal. 266 (1) (2009) 59-63.

[21] S. Nagarajan, K. Thirunavukkarasu, C.S. Gopinath, J. Phys. Chem. C 113 (17) (2009) 7385-7397.

[22] S. Penner, P. Bera, S. Pedersen, L.T. Ngo, J.J.W. Harris, C.T. Campbell, J. Phys. Chem. B 110 (48) (2006) 24577-24584.

[23] Y. Ma, F. Guazzone, Annales de Chimie: Sci. des Mat. 32 (2) (2007) 179-195.
This work was realized in the frame of FISRMIUR project " $\mathrm{H}_{2}$ puro da gas naturale mediante reforming a conversione totale ottenuta integrando reazione chimica e separazione a membrana" and of the EU Network of Excellence IDECAT (NMP3-CT-2005-011730).

[24] S.-K. Ryi, N. Xu, A. Li, C.J. Lim, J.R. Grace, Int. J. Hydrogen Energy 35 (6) (2010) 2328-2335

[25] R. Bhandari, Y.H. Ma, J. Membr. Sci. 334 (1-2) (2009) 5063.

[26] S. Abate, C. Genovese, S. Perathoner, G. Centi, Catal. Today 145 (2009) 63-71.

[27] H.-I. Chen, C.-Y. Chu, T.-C. Huang, J. Chin. Inst. Chem. Eng. 34 (1) (2003) 91-99.

[28] H.-I. Chen, C.-Y. Chu, T.-C. Huang, Thin Solid Films 460 (1-2) (2004) 62-71.

[29] H. Gao, Y.S. Lin, Y. Li, B. Zhang, Ind. Eng. Chem. Res. 43 (22) (2004) 6920-6930

[30] A. Basile, F. Gallucci, S. Tosti, Membr. Sci. Technol. Ser. 13 (Inorganic Membranes) (2008) 255-323.

[31] D.A.P. Tanaka, M.A.L. Tanco, S.-i. Niwa, Y. oWakui, F. Mizukami, T. Namba, T.M. Suzuki, J. Membr. Sci. 247 (1-2) (2005) 21-27.

[32] W.-H. Lin, H.-F. Chang, Surf. Coat. Technol. 194 (1) (2005) 157-166.

[33] G. Strukul, R. Gavagnin, F. Pinna, E. Modaferri, S. Perathoner, G. Centi, M. Marella, M. Tomaselli, Catal. Today 55 (2000) 139-149.

[34] Y.X. Chen, Y. Zhang, H.Y. Liu, K.R. Sharma, G.H. Chen, Environ. Technol. 25 (2) (2004) 227-234.

[35] M.A. Hasnat, M.A. Islam, S.M. Borhanuddin, M.R.U. Chowdhury, M. Machida, J. Mol. Catal. A: Chem. 317 (1-2) (2010) 61-67.

[36] S. Melada, F. Pinna, G. Strukul, S. Perathoner, G. Centi, J. Catal. 235 (1) (2005) 241-248.

[37] S. Abate, G. Centi, S. Melada, S. Perathoner, F. Pinna, G. Strukul, Catal. Today 104 (2-4) (2005) 323-328.

[38] L. Shi, A. Goldbach, G. Zeng, H. Xu, J. Membr. Sci. 348 (12) (2010) 160-166

[39] L. Wang, S. Bao, J. Yi, F. He, Z. Mi, Appl. Catal. B: Environ. 79 (2) (2008) 157-162.

[40] K. Sato, T.-a. Hanaoka, S. Hamakawa, M. Nishioka, K. Kobayashi, T. Inoue, T. Namba, F. Mizukami, Catal. Today 118 (1-2) (2006) 57-62.

[41] K. Sato, T.-A. Hanaoka, S.-I. Niwa, C. Stefan, T. Namba, F Mizukami, Catal. Today 104 (2-4) (2005) 260-266.

[42] H. Orita, N. Itoh, Appl. Catal. A: Gen. 258 (1) (2004) 17-23.

[43] Y. Guo, X. Zhang, H. Zou, H. Liu, J. Wang, K.L. Yeung, Chem. Commun. (2009) 5898-5900.

[44] G. Centi, S. Perathoner, Catal. Today 143 (1-2) (2009) 145150 .

[45] J. Cizek, I. Prochazka, O. Melikhova,M.Vlach, N. Zaludova, G. Brauer,W.Anwand, W. Egger, P. Sperr, C. Hugenschmidt, R. Gemma, A. Pundt, R. Kirchheim, Physica Status Solidi C 6 (11) (2009) 2364-2366

[46] S.C. Chen, C.C.Y. Hung, G.C. Tu, M.H. Rei, Int. J. Hydrogen Energy 33 (2008) 1880-1889.

[47] S. Abate, S. Perathoner, C. Genovese, G. Centi, Desalination $200(1-3)(2006)$ 760-761 
[48] S. Abate, G. Centi, S. Perathoner, F. Frusteri, Catal. Today 118 (1-2) (2006) 189-197.

[49] S. Abate, G. Centi, S. Perathoner, C. Genovese, G. Iaquaniello, E. Lollobattista, Preprints-Am. Chem. Soc., Div. Petrol. Chem. 53 (1) (2008) 85-86.

[50] Y.S. Cheng, K.L. Yeung, J. Membr. Sci. 158 (1999) 127141.

[51] G.L. Holleck, J. Phys. Chem. 74 (3) (1970) 503-511

[52] R. Dittmeyer, V. Höllein, K. Daub, J. Mol. Catal. A 173 (2001) 135-184.

[53] J.W. Phair, R. Donelson, Ind. Eng. Chem. Res. 45 (2006) 5657-5674
[54] W. Wang, X. Pan, X. Zhang, W. Yang, G. Xiong, Sep. Purif. Technol. 54 (2007) 171-262.

[55] V.P. Bushlanov, Nanotechnol. Russia 3 (5-6) (2008) 363367.

[56] H. Barlag, L. Opara, H. Züchner, J. Alloys Compd. 330-332 (2002) 434-437.

[57] N. Mori, T. Nakamura, K.-i. Noda, O. Saki, A. Takahashi, Y. Iwamoto, T. Hattori, Ind. Eng. Chem. Res. 46 (2007) 19521958.

[58] O. Sudre, F.F. Lange, J. Am. Ceram. Soc. 75 (12) (2005) 3241-3251. 